\title{
Tredimensjonal ultralydundersøkelse i kardiologisk diagnostikk
}

\author{
Engelsk oversettelse på www.tidsskriftet.no
}

\begin{abstract}
Sammendrag
Bakgrunn. Bildediagnostikk med bruk av ultralydundersøkelse spiller en viktig rolle i kardiologien. Nye teknologiske fremskritt, som tredimensjonal fremstilling av hjertet, benyttes nå som et viktig supplement til dagens standardekkokardiografi.
\end{abstract}

Kunnskapsgrunnlag. Basert på litteraturstudier i PubMed samt egne erfaringer gir vi en oversikt over de muligheter tredimensjonal ekkokardiografi (3D-ekko) har i dagens og morgendagens diagnostikk av hjertesykdommer.

Resultater. Tredimensjonal ekkokardiografi er et viktig supplement til dagens standardekkokardiografi. Best dokumentasjon foreligger når det gjelder beregning av venstre hjertekammers volum og ejeksjonsfraksjon samt i diagnostikk av mitralklaffsykdom. Metoden har teoretisk sett også fortrinn som veiledning ved kateterbaserte intervensjoner samt ved diagnostikk av kardiomyopatier og komplekse medfødte hjertefeil.

Fortolkning. Med bedret teknologi og dermed bedre bildefremstilling vil tredimensjonal ekkokardiografi bli et enda viktigere supplement til dagens standardekkokardiografi. Spesielt viktig er mer presis preoperativ diagnostikk ved klaffefeil som veiledning av kirurgisk prosedyrevalg.

\section{Stig Urheim}

stig.urheim@oslo-universitetssykehus.no Kardiologisk avdeling

\section{Kai Andersen}

Thoraxkirurgisk avdeling

\section{Svend Aakhus}

Seksjon for hjerteultralyd

Kardiologisk avdeling

Oslo universitetssykehus, Rikshospitalet

Tredimensjonal fremstilling av hjertet ved bruk av ultralyd (3D-ekko) har i prinsippet vært tilgjengelig de to siste tiår. Ved Oslo universitetssykehus, Rikshospitalet, har metoden vært evaluert fra midten av 1990årene $(1,2)$. Målet var å utvikle bedre metoder for beregning av volum og venstre ventrikkel-masse. Dette er viktige mål for venstre hjertekammers funksjon, med betydning for behandling og pasientens prognose. De siste årene har det vært en rivende teknologisk utvikling - ikke minst med bruk av nye ultralydprober (multilineære prober) har man mulighet til å gjøre opptak i sanntid med bedre tidsoppløsning og romlig oppløsning (3). I tillegg er det utviklet mer avanserte verktøy for «offlineanalyse».

Det er også muligheter i dag for å gjøre tredimensjonale registreringer ved bruk av transoesophagusekkografi. Dette gir muligheter for enda bedre anatomisk fremstilling av strukturer, noe som er spesielt nyttig ved diagnostikk av mitralklaffsykdom. Vi vil i det følgende gjennomgå metoden basert på litteraturstudier og egen erfaring.

\section{Kunnskapsgrunnlag}

Artikkelen bygger på et skjønnsmessig utvalg av artikler som ble funnet via søk i PubMed med følgende søkeord: 3D echocardiography and - mitral stenosis (120 treff), - mitral regurgitation (398 treff), - aortic stenosis (191 treff), - aortic regurgitation (398 treff), tumors (117 treff), - stress echo (33 treff), ASD (57 treff), - VSD (27 treff). Søket ble avsluttet 30.12. 2011. Kun engelskspråklig litteratur ble vurdert. Treffene er gjennomgått og det ble gjort et skjønnsmessig utvalg der resultater fra randomiserte, kontrollerte studier og systematiske oversiktsartikler er blitt vektlagt.

\section{Hvordan blir fremstillingen «tredimensjonal»?}

Det er flere ulike metoder for «tredimensjonal» fremstilling på ultralydskjermen eller arbeidsstasjonen. Mest kjent er bruk av 3D- briller, der opptaket vises i stereosyn. Mange blir trette i øynene ved bruk av slike briller, og alternative metoder blir derfor ofte valgt.

Man kan bruke fargekoding for å få frem en dybdeeffekt - ved at de strukturer som befinner seg i samme dybde kodes med samme farge og intensitet. Lys-og-skygge-effekter gjør det også mulig å tolke bildet mer tredimensjonalt. Endelig er det utviklet en holografisk skjerm som gir en sann tredimensjonal fremstilling av hjertet uten at det trengs 3Dbriller (Setred, Forskningsparken, Oslo).

\section{Volumanalyse}

Automatisk volumanalyse med angivelse av venstre ventrikkels ejeksjonsfraksjon (EF) kan gjøres fra tre ortogonale plan (4) eller fra hele fullvolumet, med fremstilling av volumkurve i hele hjertesyklusen (fig 1). 3D-ekko har en teoretisk fordel ved at volumet ikke beregnes ut fra en geometrisk modell, men kan estimeres direkte fra fullvolumopptak. Man unngår også å gjennomskjære apeks slik at volumet blir falskt lavt, noe som ofte er tilfellet ved konvensjonell todimensjonal avbildning. Metoden er validert mot MRundersøkelse av hjertet, med god overenstemmelse for venstre ventrikkels volumer og ejeksjonsfraksjon $(2,4-7)$.

Det har imidlertid vist seg vanskeligere å estimere høyre hjertekammers volum med tredimensjonal teknikk (8). Dette skyldes dels en mer kompleks geometrisk utforming av høyre ventrikkel som gjør at det er vanskelig å få med hele volumet $i$ ett opptak, men ikke minst at høyre ventrikkels frie vegg er tynn og lokalisert mer fortil, hvor det er vanskelig å få gode ekkosignaler.

\section{Klaffefeil}

Vurdering av klaffesykdom med bruk av 3Dekko har vært validert i ulike studier. Fore-

\section{Hovedbudskap}

- Tredimensjonal ekkokardiografi er et supplement til standard todimensjonal ultralydfremstilling av hjertet

- Metoden er best dokumentert for volumberegning av venstre hjertekammer og ejeksjonsfraksjon samt ved mitralklaffsykdom

- Ved en lang rekke andre kardiologiske problemstillinger vil metoden kunne gi viktig tilleggsinformasjon 


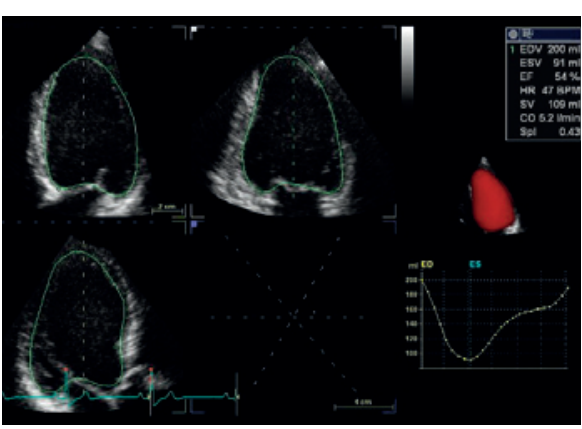

Figur 1 Fremstilling av volumkurve i hele hjertesyk lusen (nederst til høyre i bildet). Volumdata og ejeksjonsfraksjon (EF) er angitt. Figuren viser også de tre standardplanene fra fullvolumopptaket

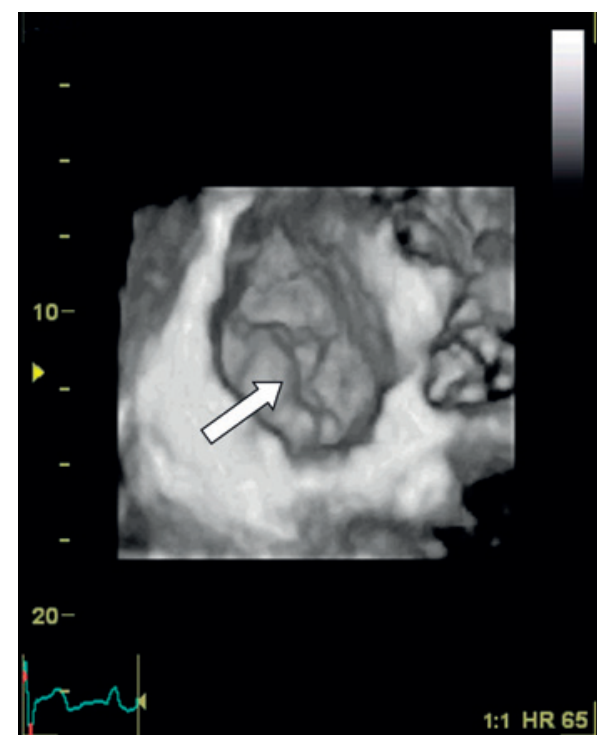

Figur 2 Transtorakalt opptak av mitralklaffen sett fra venstre atrium (surgeons view). Hvit pil markerer prolaps av bakre mitralklaffseil, som omfatter midtre og posteromediale tredel (henholdsvis P2 og P3)

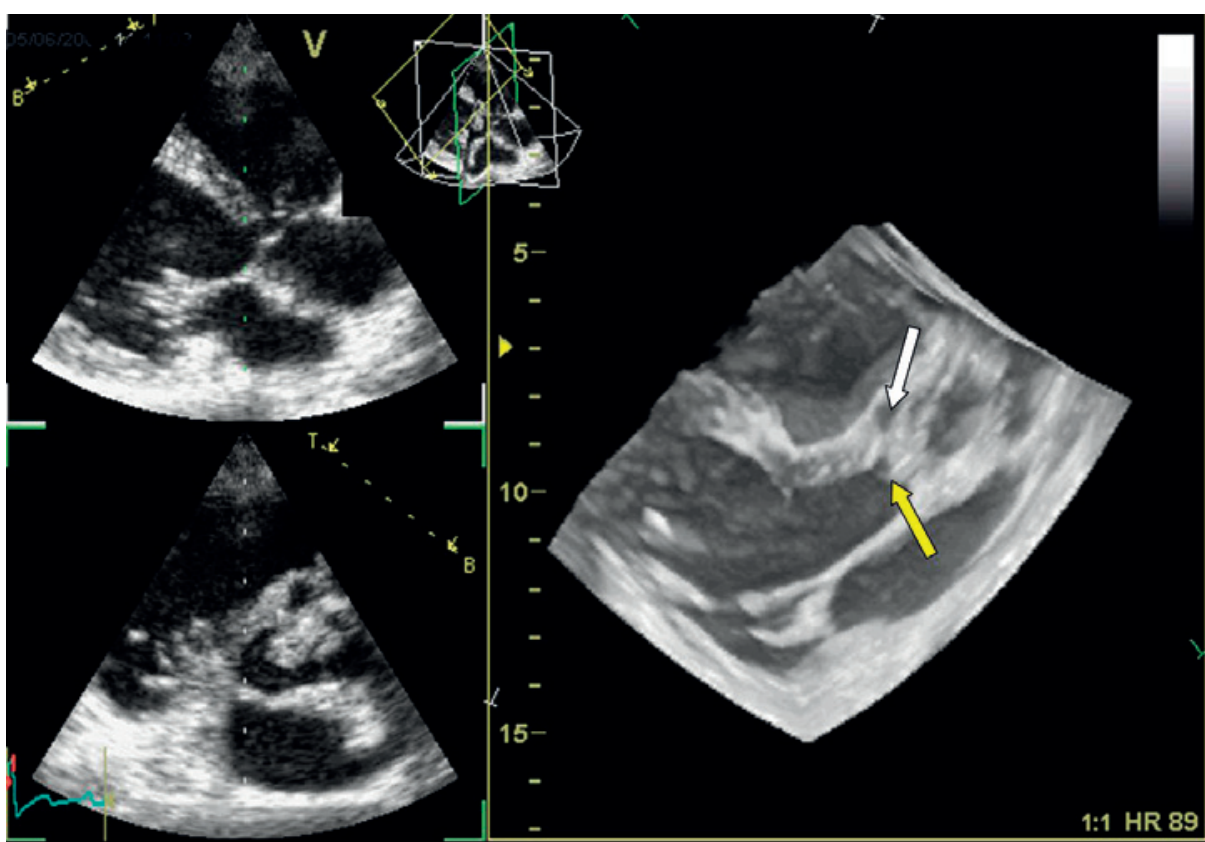

Figur 3 Transtorakalt opptak hos pasient med aortaklaffendokarditt. Gul pil markerer vegetasjon og hvit pil abscesshule fortil i aortaroten

klaffer som er best dokumentert (9-12). Det har i løpet av de siste ti år foregått en endring i den kirurgiske behandling av mitralklaffsykdom. Nye kirurgiske teknikker har muliggjort reparasjon av mitralfeilen hos mange pasienter som før måtte ha klaffeerstatning. Slik reparativ kirurgi stiller strenge krav til presis diagnostikk av mitralklaffens form og funksjon, slik at riktig kirurgisk metode kan anvendes. Pasienter med mitralklafflekkasje utredes hos oss med 3D-ekko for nøyaktig lokalisering av klaffens skade (fig 2). Vi har spesiell nytte av det såkalte kirurgiske innsyn (surgeons view) fra venstre atrium, hvor hele mitralklaffen kan fremstilles i samme bilde som vist i figur 2

I dag er todimensjonal transoesophagusekkokardiografi påkrevd før kirurgisk teknikk velges ved behandling av mitralprolaps. Interessant nok er det nylig vist at tredimensjonal utvendig ekkokardiografi (transtorakal) var likeverdig med todimensjonal transoesophagusekkografi i lokalisering av mitralklaffprolaps (10). Tredimensjonal transoesophagusekkografi var enda mer presist i diagnostikken av kommisurale prolapser, som kan være vanskelige å reparere. Dette er viktig informasjon for planlegging av kirurgisk metode ved valg av ventil versus klaffebevarende, reparativ kirurgi. Ved en rekke hjertekirurgiske sentre i Europa gjøres det nå rutinemessig 3D-ekko før mitralklaffplastikk.

Kvantitering av lekkasjer er også en viktig del av diagnostikken hos pasienter med mitralklafflekkasje. Todimensjonal fargedoppler har klare svakheter i denne diagnostikken. Studier viser at anvendelse av 3Dekko med fargedoppler er et mer robust mål for estimering av klaffelekkasje og beregning av effektivt regurgitasjonsareal (EROA) (13, 14). Tredimensjonal ekkokardiografi med fargedoppler gir unike muligheter til å fremstille vena contracta i flere plan. Dermed kan man med en enkel teknikk planimetrere arealet svarende til v. contracta $(14,15)$.

Det foreligger flere studier om evaluering av aortastenoser både med direkte planimetri (16-19) og med tredimensjonal fargedoppler for bestemmelse av slagvolum og derivering av arealet med kontinuitetslikningen $(16,20)$. Spesielt ved forekomst av septumvalk, noe som er vanlig hos eldre, var sistnevnte metode mer presis enn bruk av tradisjonell todimensjonal ekkokardiografi (20). Tredimensjonal ekkokardiografi gir også muligheter til å kvantitere aortainsuffisienser, der todimensjonal ekkokardiografi har åpenbare svakheter i dag (18).

Med nye teknikker, som perkutane prosedyrer ved klaffefeil (implantasjon av kunstig aortaventil) og reparasjon av mitralklafflekkasje med transkateterteknikk (MitraClip), vil 3D-ekko kunne ha en sentral plass i gjennomføringen av prosedyrene (21). I løpet av få år kan det også bli aktuelt med tredimensjonal ekkokardiografi for nye perkutane teknikker, ikke bare for MitraClip. Det utvikles nå (i dyremodeller) teknikker for blant annet å erstatte/reparere chordae og for innsettinng av mitralring og nye perkutane mitraventiler.

Hos pasienter med mitralstenose har metoden også vist seg å være mer presis enn de teknikker som anvendes rutinemessig i dag (12, 22-24). Fordelen med 3D-ekko er muligheten for å legge bildeplanet en face gjennom stenosens minste åpning, slik at det reelle stenosearealet blir mer presist estimert.

Vi har nytte av 3D-ekko hos pasienter med restlekkasjer etter klaffeoperasjoner. Ved paover lekkasjens lokalisering og utbredelse. Andre kliniske problemstillinger hvor 3Dekko benyttes hos oss er ved endokarditter. I tillegg til mer presis lokalisering vil man også få bedre oversikt over abscessutbredelse og eventuelle fisteldanninger (fig 3).

\section{Intrakardiale masser}

Bedømming av intrakardiale masser kan også være utfordrende, selv med todimensjonal transoesophagusekkografi. Vi har hatt nytte av 3D-ekko til bedømming av myksomer (utbredelse, hvorvidt tumor er stilket og i ett tilfelle myksomets beliggenhet i venstre ventrikkel i forhold til papillmuskulaturen). Videre har vi utelukket trombe i venstre aurikkel hvor todimensjonal transoesophagusekkografi ikke kunne utelukke dette.

Apikale «oppfyllinger» kan være vanskelige å tolke, spesielt hvorvidt det foreligger en trombe. 3D-ekko kan også her ha sine fordeler sammenliknet med 2D-ekko (25-27). Påvisning av ventiltrombose er også mulig med ny teknologi og gjøres rutinemessig hos oss der mistanke om dette foreligger. ravalvulære lekkasjer får man god oversikt 


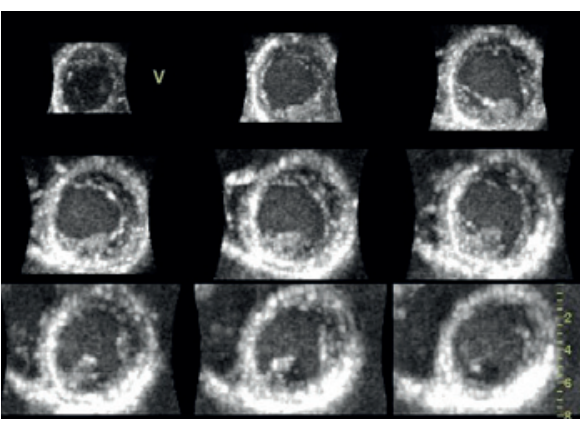

Figur 4 Kortaksesnitt av venstre hjertekammer fra fullvolumopptak hos normal person. Øverst til venstre apikale snitt, nederst til høyre basale snitt. Alle kortaksene kan fremstilles i sanntid simultant. Regionale kontraksjonsforstyrrelser kan avdekkes med denne teknikken

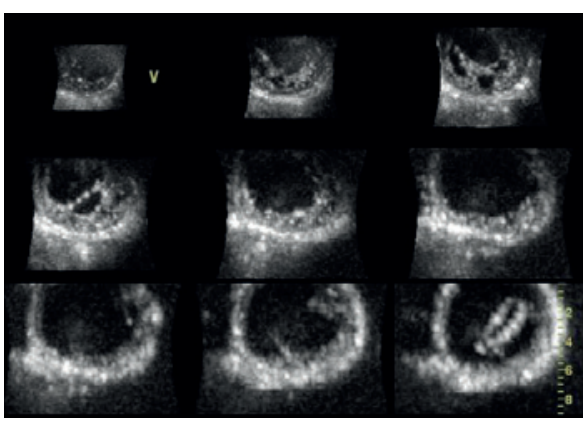

Figur 5 Kortaksesnitt av venstre hjertekammer hos pasient med manglende modning av myokard (non-compaction cardiomyopathy). I apikale snitt ses «spongiøst» vev med rikelig kryptedanning. I sanntidsfremstilling vil man kunne se betydelig nedsatte kontraksjoner av ventrikkelen

\section{Kardiomyopatier}

Ved hjelp av 3D-ekko med fullvolumopptak kan venstre hjertekammer fremstilles som multiple kortakser på skjermen (fig 4). Ved hjertemuskelsykdommer som hypertrofisk kardiomyopati får man bedre oversikt over fordelingen av hypertrofien. Spesielt ved mer apikale varianter kan dette være nyttig, da disse kan bli oversett ved rutineekkografi. Enkelte sjeldnere former for kardiomyopatier, som manglende modning av myokard (non-compaction cardiomyopathy), har karakteristiske trekk som lett kan fremstilles med 3D-ekko (fig 5). Det foreligger imidlertid foreløpig ingen god dokumentasjon på tilleggsnytten av tredimensjonal ekkografi ved ulike kardiomyopatier.

\section{Medfødte hjertefeil}

3D-ekko har flere mulige anvendelsesområder innen diagnostikk av pasienter med medfødte hjertefeil. Vurdering av atrieseptumdefekt (ASD) (28-33) kan i enkelte tilfeller være vanskelig selv med transoesophagusekkografi. Dette gjelder spesielt bedømmelse av omfanget av defekten og av hvor gode mulighetene er for festekant for en kunstig propp. Der det er store defekter med liten festekant, kan man være best tjent med kirurgisk lukking.

Tilsvarende har man anvendt tredimensjonal ultralydundersøkelse til diagnostikk og for veiledning av kateterbasert lukking av muskulære ventrikkelseptumdefekter (34). Ved mer komplekse hjertefeil kan man også teoretisk ha nytte av tredimensjonal ekkokardiografi.

\section{Myokardfunksjon}

I tillegg til globale mål for venstre hjertekammer-funksjon, slik som ejeksjonsfraksjon, er det utviklet metoder for beregning av regional myokardfunksjon gjennom bestemmelse av deformasjon og deformasjonshastigheter (35). Disse beregningene har vært basert på vanlige todimensjonale ekkoregistreringer og er begrenset til ett plan. Siden hjertet er en tredimensjonal struktur med konstant masse, vil deformasjon i én akse (x) medføre deformasjon i øvrige akser (y, z). Dette kan teoretisk løses ved tredimensjonale registreringer hvor man kan beregne deformasjonen i alle disse aksene simultant.

Bruk av 3D-ekko i diagnostikk av reversibel iskemi (stressekkokardiografi) har også en betydelig teoretisk fordel. Tredimensjonal stressekkokardiografi er i løpet av de siste årene blitt validert mot todimensjonal stressekkokardiografi $(5,36,37)$. Fortsatt er sensitiviteten noe lavere for 3D-ekko, spesielt gjelder dette fremre vegg og lateralvegg. Spesifisiteten for de to metodene er noenlunde lik (80-90\%). Det er fortsatt en utfordring at tidsoppløsningen er begrenset, spesielt ved høye hjertefrekvenser. Videreutvikling av teknologien vil forhåpentligvis bedre temporal $\mathrm{og}$ spatial oppløsning av 3D-registreringene.

\section{Ressursbruk}

I en travel klinisk hverdag er det viktig å ha med kostnad-nytte-vurderinger når det gjelder de undersøkelser vi foretar. 3D-ekko vil så langt være et supplement til en fullstendig todimensjonal ekkokardiografi. Etter vår mening bør alle sykehus som tilbyr klaffebevarende kirurgi ha 3D-ekko som en del av utstyrsparken. Ikke bare tertiære sentre vil ha nytte av teknologien - eksemplene over viser hvilken nytte andre sykehus og privatpraktiserende spesialister kan ha av den tilleggsinformasjonen 3D-ekko kan gi. Det er avgjørende at man er dedikert til oppgaven og bruker noe tid i starten for å lære seg teknikken samt holder kunnskapen ved like.

\section{Konklusjon}

Med bedret teknologi og dermed bedre bildefremstilling er tredimensjonal ekkokardiografi blitt et viktig supplement til dagens standard ekkokardiografi, både transtorakal og transøsofageal. I dag er metoden best dokumentert for kvantitering av venstre ventrikkels volum og ejeksjonsfraksjon og for kvalitativ bedømming av mitralklaffsykdom.

\section{Stig Urheim (f. 1962)}

er spesialist $i$ indremedisin og $i$ kardiologi. Han er dr.med. og overlege/forsker ved Kardiologisk avdeling, Oslo universitetssykehus, Rikshospitalet.
Forfatter har fylt ut ICMJE-skjemaet og oppgir følgende interessekonflikter: Han har mottatt honorar fra GE Vingmed og Philips for inviterte foredrag.

\section{Kai Andersen (f. 1945)}

er spesialist i kardiologi, i indremedisin og i klinisk fysiologi. Han er dr.med. og overlege ved Thoraxkirurgisk avdeling, Oslo universitetssykehus, Rikshospitalet.

Forfatter har fylt ut ICMJE-skjemaet og oppgir ingen interessekonflikter.

\section{Svend Aakhus (f. 1958)}

er dr.med. og spesialist $\mathrm{i}$ indremedisin og hjertesykdommer. Han er seksjonsoverlege ved Kardiologisk avdeling, Oslo universitetssykehus, Rikshospitalet, og professor II ved Norges teknisk-naturvitenskapelige universitet. Forfatter har fylt ut ICMJE-skjemaet og oppgir følgende interessekonflikter: Han har fått forskningsstipend fra GE Healthcare, Norge, og har avtale om produkttesting med Vingmed AS, Norge

\section{Litteratur}

Rodevand O, Bjornerheim R, Kolbjornsen $\mathrm{O}$ et al. Left ventricular mass assessed by three-dimensional echocardiography using rotational acquisition. Clin Cardiol 1997; 20: 957-62.

2. Rodevand O, Bjornerheim R, Aakhus S et al. Left ventricular volumes assessed by different new three-dimensional echocardiographic methods and ordinary biplane technique. Int J Card Imaging 1998; 14: 55-63.

3. Hung J, Lang R, Flachskampf F et al. 3D echocardiography: a review of the current status and future directions. J Am Soc Echocardiogr 2007; 20: $213-33$

4. Hansegård J, Urheim S, Lunde K et al. Semi-automated quantification of left ventricular volumes and ejection fraction by real-time three-dimensional echocardiography. Cardiovasc Ultrasound 2009; $7: 18$

5. Jenkins C, Moir S, Chan J et al. Left ventricular volume measurement with echocardiography: a comparison of left ventricular opacification, three-dimensional echocardiography, or both with magnetic resonance imaging. Eur Heart J 2009; 30: $98-106$

6. Mor-Avi V, Jenkins C, Kühl HP et al. Real-time 3-dimensional echocardiographic quantification of left ventricular volumes: multicenter study for validation with magnetic resonance imaging and investigation of sources of error. JACC Cardiovasc Imaging 2008; 1: 413-23.

7. Sugeng L, Mor-Avi V, Weinert L et al. Quantitative assessment of left ventricular size and function: side-by-side comparison of real-time threedimensional echocardiography and computed tomography with magnetic resonance reference. Circulation 2006; 114: 654-61.

8. Aune E, Baekkevar M, Rodevand 0 et al. The limited usefulness of real-time 3-dimensional echocardiography in obtaining normal reference ranges for right ventricular volumes. Cardiovasc Ultrasound 2009; 7: 35.

9. Fabricius AM, Walther T, Falk $V$ et al. Threedimensional echocardiography for planning of mitral valve surgery: current applicability? Ann Thorac Surg 2004; 78: 575-8.

10. Pepi M, Tamborini G, Maltagliati A et al. Head-tohead comparison of two- and three-dimensional transthoracic and transesophageal echocardiography in the localization of mitral valve prolapse. J Am Coll Cardiol 2006; 48: 2524-30.

11. Sugeng L, Shernan SK, Weinert L et al. Real-time three-dimensional transesophageal echocardiography in valve disease: comparison with surgical findings and evaluation of prosthetic valves. J Am Soc Echocardiogr 2008; 21: 1347-54. 
12. Zamorano J, Perez de Isla L, Sugeng L et al. Noninvasive assessment of mitral valve area during percutaneous balloon mitral valvuloplasty: role of real-time 3D echocardiography. Eur Heart J 2004; 25: $2086-91$

13. Marsan NA, Tops LF, Nihoyannopoulos P et al. Real-time three dimensional echocardiography: current and future clinical applications. Heart 2009: 95: 1881-90.

14. Sugeng L, Chandra S, Lang RM. Three-dimensional echocardiography for assessment of mitral valve regurgitation. Curr Opin Cardiol 2009; 24: 420-5.

15. Kahlert P. Plicht B, Schenk IM et al. Direct assessment of size and shape of noncircular vena contracta area in functional versus organic mitral regurgitation using real-time three-dimensional echocardiography. J Am Soc Echocardiogr 2008 21: 912-21.

16. Khaw AV, von Bardeleben RS, Strasser $\mathrm{C}$ et al. Direct measurement of left ventricular outflow tract by transthoracic real-time 3D-echocardiography increases accuracy in assessment of aortic valve stenosis. Int J Cardiol 2009: 136: 64-71.

17. Goland S, Trento A, lida K et al. Assessment of aortic stenosis by three-dimensional echocardiography: an accurate and novel approach. Heart 2007; 93: 801-7.

18. Mallavarapu RK, Nanda NC. Three-dimensional transthoracic echocardiographic assessment of aortic stenosis and regurgitation. Cardiol Clin 2007; 25: 327-34.

19. de la Morena G, Saura D, Oliva MJ et al. Real-time three-dimensional transoesophageal echocardiography in the assessment of aortic valve stenosis. Eur J Echocardiogr 2010; 11: 9-13.

20. Poh KK, Levine RA, Solis J et al. Assessing aortic valve area in aortic stenosis by continuity equation a novel approach using real-time three-dimensional echocardiography. Eur Heart J 2008; 29: 2526-35.

21. Siegel RJ, Luo H, Biner S. Transcatheter valve repair/implantation. Int J Cardiovasc Imaging 2011; 27: 1165-77.

22. Zamorano J, de Agustín JA. Three-dimensional echocardiography for assessment of mitral valve stenosis. Curr Opin Cardiol 2009; 24: 415-9.

23. Chu JW, Levine RA, Chua $\mathrm{S}$ et al. Assessing mitra valve area and orifice geometry in calcific mitral stenosis: a new solution by real-time threedimensional echocardiography. J Am Soc Echocardiogr 2008; 21: 1006-9.

24. Chapman CB, Rahko PS. Three-dimensional echocardiography and mitral valve disease. Curr Cardiol Rep 2010; 12: 243-9.

25. Müller S, Feuchtner G, Bonatti J et al. Value of transesophageal 3D echocardiography as an adjunct to conventional 2D imaging in preoperative evaluation of cardiac masses. Echocardiography 2008; 25: 624-31.

26. Hiemetzberger R, Müller S, Bartel T. Incremental use of tissue Doppler imaging and three-dimensional echocardiography for optimal assessment of intracardiac masses. Echocardiography 2008. 25: $446-7$.

27. Asch FM, Bieganski SP, Panza JA et al. Real-time 3-dimensional echocardiography evaluation of intracardiac masses. Echocardiography 2006; 23 : 218-24.

28. Georgakis A, Radtke WA, Lopez C et al. Complex atrial septal defect: percutaneous repair guided by three-dimensional echocardiography. Echocardiography 2010; 27: 590-3

29. Johri AM, Witzke C, Solis J et al. Real-time threedimensional transesophageal echocardiography in patients with secundum atrial septal defects: outcomes following transcatheter closure. J Am Soc Echocardiogr 2011; 24: 431-7.

30. Lodato JA, Cao QL, Weinert $L$ et al. Feasibility of real-time three-dimensional transoesophageal echocardiography for guidance of percutaneous atrial septal defect closure. Eur J Echocardiogr 2009; 10: 543-8.
31. Price MJ, Smith MR, Rubenson DS. Utility of on-line three-dimensional transesophageal echocardiography during percutaneous atrial septal defect closure. Catheter Cardiovasc Interv 2010; 75: $570-7$.

32. Saric M, Perk G, Purgess JR et al. Imaging atrial septal defects by real-time three-dimensional transesophageal echocardiography: step-by-step approach. J Am Soc Echocardiogr 2010; 23: $1128-35$.

33. van den Bosch AE, Ten Harkel DJ, McGhie JS et al Characterization of atrial septal defect assessed by real-time 3-dimensional echocardiography. J Am Soc Echocardiogr 2006; 19: 815-21.

34. Dall'Agata A, Cromme-Dijkhuis AH, Meijboom FJ et al. Three-dimensional echocardiography enhances the assessment of ventricular septal defect. Am J Cardiol 1999; 83: 1576-9, A8.

35. Urheim S, Edvardsen T, Torp H et al. Myocardial strain by Doppler echocardiography. Validation of a new method to quantify regional myocardial function. Circulation 2000; 102: 1158-64.

36. Abdelmoneim SS, Bernier M, Dhoble A et al. Assessment of myocardial perfusion during adenosine stress using real time three-dimensional and two-dimensional myocardial contrast echocardiography: comparison with single-photon emission computed tomography. Echocardiography 2010; 27: 421-9.

37. Badano LP, Muraru D, Rigo F et al. High volumerate three-dimensional stress echocardiography to assess inducible myocardial ischemia: a feasibility study. J Am Soc Echocardiogr 2010; 23: 628-35.

Mottatt 27.4. 2011, første revisjon innsendt 31.10. 2011, godkjent 16.8. 2012. Medisinsk redaktør Are Brean. 